\title{
Os fios emaranhados do cultivo de si e o diálogo com a pedagogia
}

\author{
The tangled threads of self-cultivation and \\ dialogue with pedagogy
}

Los hilos enredados del autocultivo y el diálogo con la pedagogía

LÚCIA SCHNEIDER HARDT(iD

\section{Resumo}

Tomando como ponto de partida o conceito de cultivo de si em Nietzsche, o artigo tem como objetivo analisar na obra do filósofo a dimensão do sujeito com vistas a pensar o campo da educação e possíveis desdobramentos pedagógicos. Nesse entorno, o artigo dialoga também com Foucault, considerando o conceito de cuidado de si para sugerir aproximações entre os dois autores e em alguma medida diferenciá-los da perspectiva socrática. O texto problematiza, sem desqualificar, as possibilidades de formação em espaços institucionais para destacar a importância do cultivar a si mesmo, pois tais práticas instauram, permitem pensar de outras formas temas da Educação e, para além dela, a nós mesmos, sejamos alunos ou mestres.

Palavras-chave: Nietzsche. Cultivo de si. Pedagogia. Educação.

\footnotetext{
a Universidade Federal de Santa Catarina Florianópolis, SC, Brasil. Doutora em Educação, email: luciashardt@gmail.com
} 


\begin{abstract}
Taking as a starting point the concept of 'self-cultivation' in Nietzsche, the article aims to analyze, in the work of the philosopher, the dimension of the subject to think the field of education and possible pedagogical developments. In this context, the article also dialogues with Foucault, considering the concept of self-care to suggest approximations between the two authors and to some extent differentiate them from the Socratic perspective. The text problematizes, without disqualifying, the possibilities of formation in institutional spaces to emphasize the importance of cultivating oneself, because these practices establish and allow to think in other ways themes of the Education and, beyond it, to think ourselves, as students or masters.
\end{abstract}

Keywords: Nietzsche. Self-cultivation. Pedagogy. Education.

\title{
Resumen
}

Tomando como punto de partida el concepto de autocultivo en Nietzsche, el artículo tiene como objetivo analizar en la obra del filósofo la dimensión del tema para pensar sobre el campo de la educación y los posibles desarrollos pedagógicos. En este contexto, el artículo también dialoga con Foucault, considerando el concepto de autocuidado para sugerir aproximaciones entre los dos autores $y$, en cierta medida, diferenciarlos de la perspectiva socrática. El texto problematiza, sin descalificar, las posibilidades de formación en espacios institucionales para resaltar la importancia de cultivarse uno mismo, porque tales prácticas establecen, nos permiten pensar de otra manera temas de educación y, además de nosotros mismos, si somos estudiantes o Maestros

Palabras clave: Nietzsche. Autocultivo. Pedagogia. Educación.

\section{Introdução}

Nietzsche foi educado em um dos melhores e mais exigentes colégios de sua época, o Colégio Pforta. Como professor, demonstrava sua preocupação com o futuro das instituições de ensino, cada vez menos exigentes e submetidas à vontade e necessidade do Estado e do mercado. O filósofo suspeita do Estado quando propaga uma educação de massas. O que consegue oferecer é muito menos do que é necessário para constituir de fato uma formação qualificada. Nietzsche, já na condição de docente, vai na direção contrária, busca e defende o rigor, a disciplina, a 
obediência (aos textos), a coerência e a liberdade para pensar, condições muito diferentes das posições utilitaristas.

É preciso preservar a cultura transmitida pela educação para que possa aparecer o genuíno de cada um dos estudantes. Trabalho demorado e difícil. Nietzsche poderia ser acusado de apresentar uma posição elitista, contudo ele está preocupado com uma formação aristocrática no sentido da cultura, e, ainda que tenha defendido a formação do gênio, nós, intérpretes dele hoje, podemos dizer que aquilo defendido por ele como professor é fazer aparecer o que cada estudante tem de genuíno, de singular. Isto está bem apresentado na Extemporânea - Schopenhauer como educador. Para isto, seria necessário destruir alguns ídolos de sua época, por exemplo: os interesses do Estado, praticamente convertido em educador, o que de fato é um absurdo para Nietzsche. Jamais o Estado pensa no melhor para a humanidade, para a cultura, mas o melhor para si mesmo, e nessa direção providencia uma formação segundo seus objetivos. Duas tendências na modificação das instituições ficavam evidentes para Nietzsche:

Duas correntes aparentemente opostas, ambas nefastas nos seus efeitos e finalmente unidas nos seus resultados, dominam hoje os nossos estabelecimentos de ensino, originariamente fundados em bases totalmente diferentes: por um lado, a tendência de estender tanto quanto possível a cultura, por outro lado, a tendência de reduzí-la e enfraquecê-la. De acordo com a primeira tendência, a cultura deve ser levada a círculos cada vez mais amplos; de acordo com a segunda, se exige da cultura que ela abandone suas mais elevadas pretensões de soberania e se submeta como uma serva a uma outra forma de vida, especialmente aquela do Estado (2003, p. 44).

Segundo Nietzsche, o que ele assiste em seu tempo são mudanças nas instituições de ensino com o propósito de se apresentarem como atuais, modernas, mas o que se vê "em boa parte são aspectos falhos e errâncias em relação à tendência sublime que originariamente presidiu sua fundação" (NIETZSCHE, 2003, p. 43). De fato, a elevação da cultura exigiria, segundo Nietzsche, outros procedimentos, outras lutas. A confiança exagerada no Estado acaba revelando que os propósitos da política podem ser devastadores. Existe uma desproporcionalidade entre o tempo para formar pessoas e o dinheiro investido. O Estado em geral foi capturado pela ganância da utilidade e tem pressa para mostrar seus dados, seus 
projetos, para preservar-se no poder. Já para Nietzsche interessa uma educação clássica, cultivada em suas nuances e desenvolvida em um tempo desprovido de pressa.

Nietzsche, considerando sua perspectiva política, acusa as instituições conforme nos apresenta Noeli Correia Sobrinho na apresentação da obra Escritos sobre educação:

por fomentarem uma cultura erudita e jornalística, que ele chama mesmo de "incultura". A afirmação da filosofia como estratégia e da cultura clássica como exemplo é a contrapartida direta da sua crítica as disciplinas especializadas como sendo incapazes, por causa mesmo da sua natureza e limites, de lidar com os verdadeiros problemas da cultura, que são os problemas da existência. A divisão do trabalho científico e a "atomização do conhecimento", segundo Nietzsche, traziam como resultado a ruptura entre conhecimento e civilização, unidade que somente a filosofia com sua visão de conjunto poderia realizar, integrando o conhecimento à vida", a cultura à natureza. Portanto, o erudito, na medida em que está totalmente mergulhado e absorvido por seu campo microscópico, está em contradição evidente com a exigência nietzschiana da "unidade da cultura" (2003, p. 21-22).

Nietzsche defende também um educador que deve priorizar o pedagógico e uma das principais tarefas é "colocar seus alunos em guarda contra si mesmos" (NIETZSCHE, 2003 p. 26). Não é bom admirar-se prematuramente, importa reconhecer o quanto de esforço é necessário para enfrentar a mediocridade do conhecimento, por isso a defesa da disciplina e da obediência em relação ao texto e ao ensino. Infelizmente, afirma Nietzsche:

os estabelecimentos de ensino da sua época se apresentavam como instituições transmissoras de uma educação ao mesmo tempo uniformizada e medíocre, utilitária e integradora, baseada neste princípio da "livre-personalidade", cujo efeito era conservar os jovens na imaturidade, na ignorância e na indiferença. A pedagogia moderna nestes estabelecimentos eram então um misto de erudição e futilidade, de cientificismo e jornalismo, ela ajuda tão somente a formar os servidores do momento, mas não concorria absolutamente para formar os homens exigidos por uma cultura elevada, como protagonistas de um destino superior (NIETZSCHE, 2003, p. 16).

Nietzsche, mesmo deixando de ser professor, continua refletindo sobre o tema da educação por toda a vida. Na condição de um filósofo interessado na cultura e já na sua fase madura, ele estabelece metaforicamente um embate com Sócrates, outro filósofo educador. 
Sócrates, afirma Nietzsche, "entendeu que o mundo inteiro dele necessitava - de seu remédio, seu tratamento, seu artifício pessoal de autopreservação. Em toda parte os instintos estavam em anarquia; em toda parte se estava a poucos passos do excesso" (NIETZSCHE, 2006, p. 21). Sócrates viu na racionalidade um remédio para superar a decadência que se anunciava, seria ela a garantia da saúde, virtude, felicidade. Será preciso imitá-lo para instaurar uma luta contra os desejos obscuros e não permitir nenhuma concessão aos instintos, que só afastaria os indivíduos da luz da razão.

Os conceitos conbece-te a ti mesmo e cuidado de si estiveram sempre atrelados, conectados. Os estudos de Foucault podem nos mostrar com profundidade essa travessia, a partir de três momentos diferentes: a) o primeiro, vinculado aos gregos e chamado momento socrático-platônico; b) o segundo momento, chamado de "idade de ouro", o qual refere-se à cultura helenística e romana; c) por fim, o momento oriundo dos textos cristãos e os sentidos do cuidado de si a partir do asceticismo cristão.

Em alguma medida, o cuidado de si garantiu ao indivíduo um conhecimento sobre si para inclusive acessar uma possível transformação e atuação com os outros. Assim, o cuidado gera conhecimento e o conhecimento modifica o indivíduo. Segundo Foucault, nosso legado cultural mais recente acabou por dar mais ênfase ao conhecimento de si e não ao cuidado de si. Como esta trajetória se definiu? Segundo Foucault, é preciso cautela na análise deste processo pois:

veremos corno a epiméleia heautoú (o cuidado de si) é realmente o quadro, o solo, o fundamento a partir do qual se justifica o imperativo do "conhece-te a ti mesmo". Portanto, importância da noção de epiméleia heautoú no personagem de Sócrates, ao qual, entretanto, ordinariamente associa-se, de maneira senão exclusiva pelo menos privilegiada, o gnôthi seautón. Sócrates é o homem do cuidado de si e assim permanecerá. E, como veremos, em uma série de textos tardios (nos estóicos, nos cínicos, em Epicteto principalmente) Sócrates é sempre, essencial e fundamentalmente, aquele que interpelava os jovens na rua e lhes dizia: “É preciso que cuideis de vós mesmos" (2006, p. 11).

Sócrates é apresentado como alguém que incita os outros a ocuparem-se consigo mesmos, e isso deve ser feito principalmente considerando a dimensão política, que requer um compromisso com os outros e com a vida na cidade. Ainda 
fica destacado nessa ação de Sócrates um cuidado de si para vencer a ignorância e acessar aquilo que os humanos têm de divino: alcançar a verdade. Em alguma medida, Nietzsche, ao criticar Sócrates, identifica uma ênfase excessiva na racionalidade, pressente nas ações do filósofo um predomínio do conhece-te a ti mesmo sobre o cuidado de si. Mas, como vimos, Foucault recomenda cautela na análise desta questão.

O segundo momento, chamado de "idade de ouro", é considerado o momento do ápice do cuidado de si e refere-se à cultura helenística e romana. Apesar deste destaque, o período apresenta alguns paradoxos, pois ficou constituído em grande parte por imperativos e reflexões pautados por uma moral exigente, rigorosa, restritiva e austera. De toda forma, neste ponto são destacados os benefícios do cuidado de si, procurando superar as limitações do período anterior para efetivamente criar condições para a autoconstituição do sujeito. Foucault afirma que, nessa perspectiva, ter cuidado consigo mesmo passa a ser um valor para todos e durante toda a vida.

O terceiro momento do cuidado de si, chamado momento cristão, em alguma medida altera, encobre o sentido do momento socrático-platônico, bem como de alguns elementos próprios do segundo período. Na obra Hermenêutica do sujeito, Foucault procura investigar o que fica encoberto e percebe que o cuidado de si no contexto socrático-platônico implica um ocupar-se consigo em direção a uma finalidade política, cuidar da cidade, cuidar dos outros, conhecer a verdade e vencer a ignorância. O cuidado com o corpo implica preservar a saúde, fazer exercícios para contemplar e realizar sua tarefa pública.

Segundo Foucault, a apropriação do conceito pelo cristianismo destaca o cuidado com a espiritualidade: o acesso à verdade somente é possível por meio da pureza da alma. As práticas mais vivenciadas implicam a auto-observação, ou seja, olhar para dentro de si mesmo; e o conhecer-se, para saber o que ocorreu dentro de si. A vida concreta e material parece ficar marginalizada, o que por fim significará a renúncia de si mesmo, e, como consequência, a condição que encaminha uma vida ascética. 
Assim, podemos afirmar que Foucault não defende particularmente nenhuma das formas do cuidado de si. Tomar qualquer uma delas para pensar nosso tempo é inviável e anacrônico. Podemos, isto sim, e parece que é isso que Foucault faz, privilegiar uma reflexão considerando as nuances do conceito, destacar alguns aspectos, por exemplo a filosofia estoica, visando relacionar o sujeito da ação com o princípio da imanência ética que fundamenta a crítica foucaultiana ao sujeito. Ele mesmo nos ajuda a entender qual foi o foco de sua investigação:

Temos pois, com o tema do cuidado de si, uma formulação filosófica precoce, por assim dizer, que aparece claramente desde o século $V$ a.c. e que até os séculos IV-V d.C. percorre toda a filosofia grega, helenística e romana, assim como a espiritualidade cristã. Enfim, com a noção de epiméleia heautou, temos todo um corpus definindo uma maneira de ser, uma atitude, formas de reflexão, práticas que constituem uma espécie de fenômeno extremamente importante, não somente na história das representações, nem somente na história das noções ou das teorias, mas na própria história da subjetividade ou, se quisermos, na história das práticas da subjetividade. De todo modo, é a partir da noção de epiméleia heautou que, ao menos a título de hipótese de trabalho, pode-se retomar toda esta longa evolução milenar (século $\vee$ a.c. - século $\vee$ d.C.), evolução milenar que conduziu das formas primeiras da atitude filosófica tal como se a vê surgir entre os gregos até as formas primeiras do ascetismo cristão! Do exercício filosófico ao ascetismo cristão, mil anos de transformação, mil anos de evolução - de que o cuidado de si é, sem dúvida, um dos importantes fios condutores ou, pelo menos, para sermos mais modestos, um dos possíveis fios condutores (FOUCAULT, 2006, p. 15)

Foucault está, também, interessado em saber porque o conbece-te a ti mesmo parece ter prevalecido sobre as tecnologias do cuidado de si. "O que ocorreu para que se tenha privilegiado tão fortemente, para que se tenha dado tanto valor e tanta intensidade ao 'conhece-te a ti mesmo' e se tenha deixado de lado, na penumbra ao menos, esta noção de cuidado de si?”" (FOUCAULT, 2006, p. 15-16).

Nos argumentos apresentados por Foucault, fica demonstrado que o conbece-te a ti mesmo tem, em termos morais, compromissos mais ajustados às necessidades da cidade. Faz aparecer o sujeito cognoscente, capaz de, pela razão, tomar decisões e interferir na vida social. Parece que aos poucos o conceito descuida-se disso, centrase no indivíduo, marginalizando em parte o debate sobre a cidade.

Indaga Foucault: 
por que, a despeito de tudo, a noção de epiméleia heautou (cuidado de si) foi desconsiderada no modo como o pensamento, a filosofia ocidental, refez sua própria história? O que ocorreu para que se tenha privilegiado tão fortemente, para que se tenha dado tanto valor e tanta intensidade ao "conhece-te a ti mesmo" e se tenha deixado de lado, na penumbra ao menos, esta noção de cuidado de si que, de fato, historicamente, quando averiguamos os documentos e os textos, parece ter antes enquadrado o princípio do "conhece-te a ti mesmo" e constituído o suporte de todo um conjunto que é, afinal de contas, extremamente rico e denso de noções, práticas, maneiras de ser, formas de existência, etc.? Por que este privilégio, para nós, do gnôthi seautón às expensas do cuidado de si? (2006, p. 15-16).

Por sermos herdeiros de uma ênfase conferida não ao cuidado de si, mas ao conhece-te a ti mesmo, podemos concordar com Marcello e Fischer (2014) quando afirmam:

o '“conhece-te a ti mesmo' eclipsou o 'cuida de ti mesmo', porque nossa moral, uma moral do ascetismo, não parou de dizer que o si é a instância que se pode rejeitar" (Foucault, 1990, p. 54). A segunda razão, e talvez a mais importante, estaria relacionada a um "momento cartesiano", o qual, a um só tempo, requalifica o conhecimento de si (gnôthi seautón) - "conhece-te a ti mesmo" - e desqualifica o cuidado de si (epiméleia heautoû) (Foucault, 2004b, p. 18). Qualifica o conhecimento de si, pois o coloca como base para a existência inarredável e indubitável do ser - ao contrário de toda a incerteza e risco a que o ser é exposto por meio do cuidado de si. Desqualifica o cuidado de si porque desfaz o laço sólido que une a (instável) estrutura do sujeito como tal e seu necessário processo de permanente transformação (p. 167)

O que Foucault nos alcança por meio de sua pesquisa é a afirmação de que a constituição do ser humano, como um tipo específico de sujeito, ou seja, subjetivado de determinada maneira, só é possível pelo "caminho" do corpo (2006, p. 168). Contudo, nem sempre esse pressuposto foi considerado na história. Adverte Foucault: "não se deve fazer passar o cuidado dos outros na frente do cuidado de si; o cuidado de si vem eticamente em primeiro lugar, na medida em que a relação consigo mesmo é ontologicamente primária" (FOUCAULT, 2006, p. 271). Em alguma medida, Foucault retoma a história e os diferentes momentos do conceito para nos indagar: Como nos tornamos o que somos? E o que eventualmente poderíamos recusar, considerando o que nos tornamos?

Nossa travessia pela filosofia por meio dos conceitos conhece-te a ti mesmo e cuidado de si não teve como objetivo esgotar o assunto e tampouco retomar toda a pesquisa realizada por Foucault. A intenção foi mostrar o deslocamento de um 
conceito no tempo, e de como tal perspectiva adquire novas nuances em função das tensões vividas pelo indivíduo.

Neste cenário, e de uma forma singular, Nietzsche também debruçou-se sobre os dois conceitos aqui referenciados. Afinal, na crítica que faz a Sócrates ele denuncia uma excessiva vontade de correção do indivíduo com uma ideia de gosto vinculado ao bem moral. E, neste ponto, Nietzsche inicia sua crítica, pois não alinha a dimensão de gosto e correção aos preceitos morais em vigor. Nietzsche despreza em parte o que parece nos orientar moralmente para afirmar que é preciso dar tensão, dar lugar à vontade de potência do indivíduo para não aprisioná-lo aos preceitos coletivos, às demandas dos rebanhos. E sua trajetória como filósofo acaba por elaborar outra pergunta: afinal, como tornar-se o que se e?

Uma cultura autêntica não pode desejar a formação de indivíduos em série; por isso Nietzsche defende uma educação individualizada pautada pelo cultivo de si. Temos aqui que a abordagem da questão da educação é um ato de resistência para enfrentar a submissão atrelada aos interesses de uma economia de mercado pautada pelo adestramento e preparação para o mercado de trabalho.

Segundo Costa Dias, a educação a serviço do Estado não é mais que um instrumento de manutenção do status quo, a formar cidadãos dóceis para o mercado. Essa é a educação propalada no tempo de Nietzsche. Não estamos também capturados por esta lógica? Nietzsche define tal realidade como um "processo de mediocrização universal", alimentado por uma "pobreza de espírito pedagógico" (COSTA DIAS, 2016, p. 170-171).

$\mathrm{Na}$ direção inversa, Nietzsche defende a educação como cultivo de si, em que seria possível ver a si mesmo como obra de arte, a ser sempre melhorada e burilada ao longo de toda a vida. Assim, o cultivo de si em Nietzsche não está apenas sintonizado com o conceito antigo do cuidado de si, contudo tem algumas conexões que são ampliadas e esteticamente modificadas para defender seu projeto filosófico. Implica um ocupar-se consigo mesmo para garantir buscar aquilo que é genuíno em cada um de nós. Assim como a pesquisa de Foucault pretende decifrar um conceito no tempo, Nietzsche cria um conceito para fazer a defesa da singularidade, da diferença e também uma espécie de resistência aos apelos do 
Estado. Ainda que a sociedade necessite de instituições, precisamos preservar espaços para que o indivíduo tenha oportunidades de criar horizontes formativos mais livres e estéticos. Não podemos entregar nossa vida à nenhuma instituição, seja ela qual for.

\section{Como começar a refletir sobre a educação em Nietzsche?}

Como compreender na obra de Nietzsche a dimensão do sujeito que habita um corpo? Como desvendar o lugar do indivíduo? Afinal, considerando o contexto da educação, quem pode ser disciplinado, educado, cultivado se estamos sempre implicados pelo enigma do indivíduo? Este é o tema que vamos tentar aprofundar. Talvez para a Filosofia esse enigma seja menos importante, para a educação, contudo, parece fundamental. Onde ficou o sujeito? Podemos de fato afirmar que ele morreu, desapareceu? Mas então quem avaliamos, com quem dialogamos, como fazer acontecer uma trajetória pedagógica com cada aluno que interagimos? Não são suficientes respostas evasivas. O grande problema deste artigo, portanto, é: Ainda temos um aluno para acompanhar, cobrar, destacar diferenças nos processos formativos, exigir, e mais, fazê-lo praticar o cultivo de si mesmo para nos surpreender?

Podemos começar nossa reflexão ${ }^{1}$ reconhecendo que os conceitos de disciplina e cultivo constituem a filosofia de Nietzsche. Como já referimos anteriormente, a dimensão da disciplina que aqui estamos destacando prioritariamente implica um compromisso pedagógico, ou seja, no processo de formação é preciso ler, escrever e pensar considerando uma atenção disciplinada com a língua, com o texto, com a escrita.

\footnotetext{
${ }^{1} \mathrm{Na}$ argumentação que segue busquei inspiração também em uma palestra de João Constâncio, Professor do Departamento de Filosofia da Universidade de Lisboa (IFILNOVA), realizada em um Café Filosófico publicado em 24 de outubro de 2014 tendo como tema: Um mundo sem sujeito? Disponível em: <https://www.youtube.com/watch?v=EQQLsDNNh80>. Acesso em: 14 jun. 2019.
} 
Perguntar pelo aluno que ainda temos significa também indagar qual mestre ainda existe. $\mathrm{O}$ que de fato ele pode fazer em termos pedagógicos, em última instância, sugere a existência de um sujeito. Estamos diante de tipos de mestres e tipos de alunos cultivados ao longo do tempo e que nos permitem pensar, em meio a muitas tensões e conflitos, o que ainda cabe fazer no campo da educação. De toda forma, a ideia do cultivo implica discutir o conceito de sujeito.

Para discutir a ideia do sujeito, dialogo com os textos de Nietzsche e seus comentadores. Existe uma complexidade de posições em relação a este tema e muitas controvérsias em relação à função do sujeito. Contudo, também os comentadores destacam que não podemos nos fixar "apenas no patamar críticocorrosivo do conceito de sujeito em Nietzsche” (PASCHOAL, 2018, p. 94) já que a “própria construção argumentativa do filósofo por meio de suas obras evidenciaria o fato mais elementar de que um discurso é sempre produzido por um sujeito interessado em produzir efeitos” (p. 95), no caso, ele mesmo, como filósofo. Assim, podemos dizer que em Nietzsche não está declarada a morte do sujeito. Por meio de uma crítica a um determinado entendimento desse conceito, existe sim o enfrentamento de uma perspectiva metafísica e em contraponto a isso a afirmação da possibilidade de um sujeito plural, constituído por uma variedade enorme de forças e impulsos que necessitam sempre de uma espécie de coordenação e hierarquia destas forças.

Segundo Paschoal (2018), a crítica de Nietzsche se dirige àquela concepção que compreende o sujeito como uma unidade autônoma, capaz de conhecer a si mesmo e o mundo ao seu redor e de tomar decisões e agir livremente nesse mundo. A pedagogia flerta com essa concepção e nesses termos defendemos uma outra pedagogia, que enfrentasse esta lógica para pensar outros desdobramentos para a educação. A tese defendida nesse artigo pretende tratar a ideia de que o pressuposto do cultivo de si é uma das alternativas para enfrentar essa concepção de sujeito autônomo e paradoxalmente defender que existe um corpo diante de nós, que se desloca e pensa sempre com alguma singularidade. Assim, a tarefa nietzschiana é justamente fazer uma crítica ao quadro conceitual cartesiano, enfrentando o 
fundamento metafísico orientador que serve de sustentáculo para o conhecimento e para a existência do homem e suas relações cotidianas.

Em Nietzsche (é preciso situar os pensamentos do autor, em sua obra), existe uma crítica tanto ao livre-arbítrio quanto ao determinismo. Significa dizer que o sujeito não é absolutamente livre, autônomo, para decidir sobre suas ações e tampouco é apenas conduzido e manipulado pelas contingências. De toda forma, nenhum dos conceitos é arbitrário, eles são uma espécie de signo, de sintoma de determinadas avaliações pulsionais. Tipos humanos precisam deste discurso para consolidar um determinado poder na sociedade. A tese do livre-arbítrio cria o poder da moral e compromete o sujeito em relação às suas escolhas, fazendo surgir um tipo determinado pela moral e pela culpa. Permite culpabilizar o outro por aquilo que não alcançou, não escolheu, atitude muito frequente no cenário pedagógico.

O livre-arbítrio tem também uma função niveladora, socializando um tipo de ser humano que de certa forma impede uma singularidade. Cultivar e disciplinar os sujeitos nessa direção produz um tipo de educação. Como signo, como sintoma, expressa um arranjo que não rejeita absolutamente o pressuposto do livre-arbítrio, como se, em um modelo dualista, uma outra opção seria então descoberta. Nietzsche quer outra coisa de nós, quer nos fazer pensar sobre os efeitos tanto de um modelo quanto de outro, sem imaginar que poderia extinguir algum deles; mas o que interessa é decifrar como esses arranjos produzem efeitos numa sociedade.

Ao discutir o sujeito, Nietzsche está enfrentando termos como eu, alma, causa e efeito, liberdade da vontade, linguagem e seus efeitos. Em alguma medida, tais nomes expressam uma ficção sobre a ideia de sujeito que, assumida em parte na modernidade, consagra uma orientação em termos formativos. Contudo, temos na modernidade elementos que foram destacados que merecem nossa atenção, por exemplo, o próprio exercício da dúvida, presente em Descartes e, como diz Nietzsche, abandonado por ele muito cedo, para então tomar e definir outras orientações para o nosso pensamento. Assim, como o conceito de sujeito, merece nossa atenção também o conceito de ação. Afinal, o que provoca a ação do sujeito? Como podemos compreender isso no contexto da educação? 
Quando Nietzsche afirma "tudo é ação" (2009, p. 46) ele está exatamente recusando que a ação seja efeito da razão. Ela é a expressão de uma luta pulsional que acontece no corpo e que ao expressar-se tem em si também o pensamento que sempre habita a superfície, mas tem por outro lado muitas forças que explodem e surpreendem quando aparecem. Existe uma multiplicidade de motivações que geram a ação e a consciência talvez seja a menor delas.

Apesar disso, Nietzsche não abandona o debate sobre a subjetividade. Em alguma medida as ações são nossas, a ação é inseparável de um corpo, contudo são decorrentes de uma vida pulsional onde a consciência tem um pequeno lugar. Seu texto é ainda mais esclarecedor:

Ainda há ingênuos observadores de si mesmos que acreditam existir "certezas imediatas"; por exemplo, "eu penso", ou, como era superstição de Schopenhauer, "eu quero": como se aqui o conhecimento apreendesse seu objeto puro e nu, como "coisa em si", e nem de parte do sujeito nem de parte do objeto ocorresse uma falsificação. Repetirei mil vezes, porém, que " certeza imediata", assim como "conhecimento absoluto" e "coisa em si", envolve uma contradictio in adjeto [contradição no adjetivo]: deveríamos nos livrar, de uma vez por todas, da sedução das palavras! Que o povo acredite que conhecer é conhecer até o fim; o filósofo tem que dizer a si mesmo: se decomponho o processo que está expresso na proposição "eu penso", obtenho uma série de afirmações temerárias, cuja fundamentação é difícil, talvez impossível - por exemplo, que sou eu que pensa, que tem de haver necessariamente um algo que pensa, que pensar é atividade e efeito de um ser que é pensado como causa, que existe um "Eu", e finalmente que já está estabelecido o que designar como pensar - que eu sei o que é pensar. Pois se eu já não tivesse me decidido comigo a respeito, por qual medida julgaria que o que está acontecendo não é talvez "sentir", ou "querer"? Em resumo, aquele "eu penso" pressupõe que eu compare meu estado momentâneo com outros estados que em mim conheço, para determinar o que ele é: devido a essa referência retrospectiva a um "saber" de outra parte, - ele não tem para mim, de todo modo, nenhuma "certeza" imediata (NIETZSCHE, 1992, p. 21-22).

Com esta afirmação, Nietzsche problematiza o ato de pensar e analisa como ele se assenta em um cenário metafísico, pautado por causas e efeitos, encadeamentos lógicos que tomados como verdades parecem convincentes e, de alguma forma, cultivam no humano uma espécie de convicção do seu pensar como uma verdade. Mas o filósofo, diz Nietzsche, deveria insistir: Por que sempre a verdade?

Mesmo com esta afirmação de Nietzsche, não está em questão eliminar o sujeito, mas pelo contrário, existe um esforço em mostrar em que medida ainda 
somos ingênuos quando acreditamos apenas na força da razão. Apesar disto, Nietzsche não autoriza essa interpretação e nem essa prática do vale tudo. O alerta que faz é que devemos pensar e interpretar melhor e mais sofisticadamente o que acontece por meio das ações humanas. As ações exprimem a vida pulsional e a vida política em vigor nos diferentes contextos, intensificando o surgimento de alguns tipos humanos. É preciso interpretar o subterrâneo do organismo humano, suas pulsões e como os sistemas (sejam eles quais forem: partido, instituição, religião) solicitam, cultivam e disciplinam os corpos para determinadas ações. Existe um horizonte social e político que acomoda, cultiva e compartilha determinadas ações desejáveis. Neste esforço, define-se uma moral dada como adequada. Nosso esforço enquanto aqueles que desejam espiritualizar sua vida pulsional está em genealogicamente investigar esses cenários, entornos e poderes.

Dessa forma, não existe qualquer substância a ser invocada como sua fonte ou origem, o que existe são configurações provisórias que atravessam o "sujeito" e nos permite compreender de que modo a subjetividade torna-se capaz de ser apreendida em seu devir, criando novas perspectivas sem conectar-se com o pensamento metafísico. Então esse filósofo não matou o sujeito, ele próprio se coloca como pensador, portanto tem um querer que se expressa num corpo que tem uma vida pulsional que em função de uma necessidade exerce uma liberdade: qual orientação e qual cultivo estão nos conduzindo?

Viver segundo a inocência do devir exige uma outra presença no mundo que deveria cultivar o enfrentamento do medo, a coragem de prosseguir sem ter previamente a direção definida e alegrar-se com a novidade que pode aparecer sem nenhuma previsão.

Nesse caminho, Nietzsche critica o determinismo como criticou o livre arbítrio, ou seja, abrir mão de uma normatividade a priori não nos autoriza a afirmar que seremos previamente definidos pelos nossos contextos. Existe sempre um querer, que é uma explosão de forças, sempre desproporcional a considerar causa e efeito, que designa uma espontaneidade humana produzida pelo que é vivo em todos nós. Se o determinismo pretende pelo poder nos configurar de formas interessadas para nos ajustar ao sistema, o filósofo da cultura e do espírito nos 
ensina a escapar em parte disso. Ao interpretar as relações orgânicas, políticas e sociais, sugere que nossa força não veio apenas para ajustar-se, mas ela pode explodir, espontaneamente, como uma força desproporcional àquilo que seria esperado de nós. E sem converter-se em violência. Assim, daria para arriscar que, em Nietzsche, a força do espiritual é sempre maior que qualquer intenção material. Testar uma subjetividade que a princípio não é moral, mas ao mesmo tempo é responsável por estar no mundo e definir como deseja ocupar este espaço. Zaratustra, o mais sofisticado personagem de Nietzsche, ama a humanidade e por isso se desloca, erra, opta por estratégias equivocadas, reconfigura suas escolhas, quer falar com todos, desiste, recomeça e busca interlocutores. Contudo, sua vontade de potência explode de várias formas por amor ao mundo. E nem sempre serão movidas pela razão apenas.

Neste ponto vale uma indagação: nós, educadores, explodimos por amor ao mundo? Ou para ajustar melhor todos os estudantes ao que já está configurado? Zaratustra quer livrar a humanidade do niilismo, defende o amor à terra, à vida, ao querer que explode para cultivar-se esteticamente e valorizar a vida. A própria vida do filósofo é a prova do seu esforço. Ele inicialmente encanta-se pelo pessimismo de Schopenhauer, pela arte mobilizadora de Wagner, e em sua trajetória mostra seu enfrentamento dos cultivos que foram feitos em seu corpo para superar a forma pessimista e transvalorar em si mesmo o valor da vida. Superou em si mesmo, no corpo, o pessimismo, incorporou a inocência do devir. Nesse esforço, é em suas obras retórico em excesso, cria personagens, escandaliza por meio de certas práticas, palavras, ironiza, usa o martelo para chamar a atenção do leitor. O que fazemos nós para chamar a atenção de nossos alunos na tentativa de fazê-los afirmar a vida, também a vida escolar e acadêmica?

A nossa natureza é plástica, somos transformados pelo que nos afeta. Não há identidade fixa, enquanto nos deslocamos existe um tanto de espontaneidade que surge do que nos afeta sem que tenhamos controle absoluto disso. Não existe uma causa que possa ter garantia de uma ação. Uma suposta boa aula não exatamente garante a aprovação e participação de todos os alunos. Contudo, existem alunos, existem quereres, existem singularidades. O que então vemos quando estamos em aula? 
Vemos corpos com nomes que, em função de uma multiplicidade de afetos, coordenam forças em disputas de uma forma singular e sempre provisória. Não estamos diante de consciências apenas, mas de organismos vivos que de alguma forma designam um querer. Por vezes, inclusive, não estão em aula. Talvez pudéssemos afirmar que temos um arbítrio, contudo ele não é livre, está vinculado a afetos e pulsões em constante turbulência. Seria então a desordem plena? O caos da escola e da sala de aula estaria justificado? A resposta é bem outra: por outra avaliação, estamos diante de quereres que podem ter outra hierarquização, regulação que até o momento conhecemos. Podemos fazer surgir tipos de alunos e mestres interessados na explosão de forças para hierarquizá-las em direção a um amor ao mundo e à vida escolar/acadêmica. Desenvolver a capacidade de ser legislador de si enquanto implicado por um processo de educação, de formação, ou melhor, autoformação. O tempo no exercício da docência já nos ensinou que esse querer não se estabelece em todos os corpos. Outros desejos, forças e impulsos tomam esses corpos e nos cabe perguntar: o que fazer diante disso nas instituições?

As instituições de ensino são lugares de muitas experiências, das mais sublimes até as menos defensáveis. Mas é o lugar também apropriado para a espiritualização das experiências. Romper com certas normatividades e ser capaz de construir outras. Não desistir tão facilmente de estudantes, mas provocá-los retoricamente (como nos ensina Nietzsche) criando personagens, cenas, textos com o intuito de afirmar a vida que pode ser praticada em uma instituição para muito além daquilo para o qual ela parece querer nos conduzir. E reconhecer que escapar da instituição também pode ser uma alternativa para afirmar a vida.

Existe uma espécie de vontade de emancipação humana em Nietzsche? Enquanto um moderno, parece existir sim. Afinal, ele quer nos livrar do absurdo, do caos, da vida sem sentido, onde tudo vale. Se nisso estiver um tanto de emancipação própria dos modernos, então Nietzsche também isso nos oferece. Vale apenas destacar que em Nietzsche isso jamais acontecerá controlando a natureza, será preciso compreendê-la, inclusive quando explode, e, com esta força, pensar em tipos humanos não ajustáveis, mas capazes de espiritualizar suas experiências para dar sentido à vida e amar o mundo de muitas maneiras. 


\section{Como viver nas instituições de ensino?}

Esta abordagem não é uma apologia ao fim das instituições e dos sistemas de toda ordem. Nossas vidas existem em lugares concretos, trata-se de entender que materialidade é essa. Nietzsche, ainda jovem e como professor, inclusive, destacou a força da disciplina e da obediência como critério para a formação humana. Isso significou rigor com a língua, com os textos a serem lidos, com a escrita, com o tempo da escuta para que efetivamente a ação do aluno possa acontecer. As instituições educativas são importantes e deveriam cumprir seu papel. Contudo, nesse entorno também temos forças que exigem certos ajustamentos injustificáveis. O próprio Nietzsche anunciava: "não suportarei esta atmosfera acadêmica por muito tempo" (NIETZSCHE, 2012, p. 174).

Nesse ponto, queremos retomar a ideia do cultivo de si, que é, no nosso ponto de vista, um salto qualitativo em relação ao cultivo e à disciplina. Em alguma medida, podemos cair na armadilha de acabar alcançando a ideia socrática do cuidado de si. Tentaremos evitar isso, e nesse ponto também Foucault pode ajudar, considerando sua interpretação de Nietzsche. Da mesma forma que já anunciado anteriormente, tentaremos também superar a perspectiva dualista de análise que nos conduziria a rejeitar Sócrates para afirmar Nietzsche. Não se trata disso, pois o que está em Sócrates tem efeitos em muitas outras possibilidades de discussão dos processos formativos, mas que não nos parece a mesma coisa que Nietzsche tem interesse em nos chamar a atenção por meio do conceito do cultivo de si.

Colocaremos nossas lentes no que Nietzsche pretende nos dizer, o que não impede que outros destinem suas lentes para Sócrates. Por vezes até podemos implicar as duas lentes e os olhares, contudo esse não é o foco deste artigo. Podemos concordar com Acampora que a disputa de Nietzsche com Sócrates:

resulta em sua tarefa de transvalorar o sentido da existência humana. Nietzsche prevê que vencer Sócrates exige superá-lo em vez de denegri-lo. Uma vez que parte do seu problema com Sócrates é o suposto julgamento último do filósofo grego quanto ao valor da existência, ele se empenha em imaginar a mais afirmativa de todas as atitudes possíveis perante a vida. Nietzsche explora a possibilidade de direcionar o desejo a favor da vida e como fazê-lo, refletindo sobre a diferença resultante disso - projeto que define seus escritos de Zaratustra até ao menos a 
Genealogia e é um ponto central de sua investigação mais ampla sobre o valor dos valores, dominando sua obra pelo resto de sua vida filosoficamente produtiva (ACAMPORA, 2018, p. 124).

Segundo Nietzsche, Sócrates desintegra partes importantes do agon homérico pautado por uma disputa que afirma a vida e poderia trazer excelência inclusive para a vida social. Esta excelência efetiva-se pela oposição entre os sujeitos que, levados a coordenar formas de interação social, deveriam esgotar nas disputas todos os argumentos possíveis para canalizar a agressão e facilitar sua expressão criativa. Ao impedir esse movimento, Sócrates debilita aquele que se opõe a ele, já que o outro ainda não acessou plenamente o racionalismo socrático. Atribui em excesso o valor à inteligibilidade e não tolera, como diz Acampora, "a tendência ao indiscernível e ao ambíguo que o dionisíaco promove" (2018, p. 128). Apenas as facetas do apolíneo são destacadas e vistas como adequadas para apresentar um mundo bom e verdadeiro. Assim, o cuidado de si implica dirigir-se a um encontro com o racionalismo socrático, capaz de orientar o sujeito clamando por "ações corretivas a cada pequena coisa obscura que encontra" (p. 129).

Nossa aposta é que Nietzsche se diferencia totalmente dessa perspectiva de Sócrates e isso fica mais claro na obra Zaratustra. Os fios estão emaranhados, mas estão tecidos, parece que para anunciar um querer para além de qualquer sistema pautado apenas pela razão e pela inteligibilidade.

Segundo Stegmaier:

Nietzsche apresenta em Assim falava Zaratustra um "mestre" que, inicialmente, é escarnecido, mas que é sempre mais admirado e, por fim, é venerado como um deus, que 'sucumbe' e quer sucumbir com suas doutrinas. Doutrina é aquilo que alguém pode transmitir a outrem, sem que o sentido se altere, aquilo que todos podem compreender da mesma forma, apesar das pressuposições diferentes. Zaratustra ensina as doutrinas com as quais Nietzsche se tornou famoso, as doutrinas da morte de Deus, do além-do-homem, da criação, da vontade de potência e, sobretudo, do eterno retorno do mesmo. Contudo, Nietzsche permitiu que somente seu Zaratustra as ensinasse, e ele não queria também ser confundido com Zaratustra. Por isso, pode-se supor que Nietzsche problematize no Zaratustra o ensinamento de doutrinas mesmo e, com isso, a compreensão e a necessária má compreensão enquanto tal (2009, p. 14). 
Com recursos retóricos e com o próprio personagem Zaratustra, fica insinuada uma ironia entre o que seja uma doutrina do ensinar a ponto de Nietzsche brincar com seu personagem que melhor seria falar de antidoutrinas. De certa forma reconhecendo que enquanto ensinamos não temos nenhuma garantia do que é entendido, compreendido. Trata-se de mais uma dura crítica à razão e suas possibilidades. Trata-se, assim, de um limite de qualquer instituição e sistema. Eles não podem tudo mesmo. Existe uma espécie de solidão no entendimento. Mas nesse exercício de solidão em Zaratustra também houve um encontro com a felicidade, na relação com o que ficou compreendido, e de imediato também vem a vontade de ensinar e compartilhar. E de novo ao imaginar e ensinar enfrenta o fracasso, não consegue se comunicar, é recusado pelo público.

Cultivar a si mesmo implica lidar com isso, aquilo que fortalece e anima e o fracasso que nos afeta e nos entristece. Até compreender como aquilo que cultivamos em nós pode ser expressão de um amor ao mundo em várias outras direções. Zaratustra de repente não quer mais ensinar, aprendeu com seu fracasso e agora: "ele quer ser somente "poeta, decifrador de enigmas e redentor do acaso"" (NIETZSCHE, 2011, "De velhas e novas tábuas", \$3). Valeria aqui dizer que, na filosofia, vários outros autores também fizeram isso, portanto não estamos desmerecendo esse legado filosófico. Desejamos aqui discutir o que aparece por meio do personagem Zaratustra como um caminho pedagógico mais individual, solitário e que fica expresso na ideia do cultivo de si. Essa perspectiva desse artigo é aqui dirigida como desafio para alunos e mestres. Apesar de habitarmos instituições, podemos nos colocar para além de seus objetivos, tarefa árdua e talvez rara. Stegmaier nos ajuda a entender quando afirma:

Segundo Nietzsche, compreende-se mal a filosofia, quando ela pretende fornecer doutrinas; doutrinas "para todos" seriam doutrinas para "ninguém". Mas considera que também dele são esperadas doutrinas, e sabe que ele permanecerá "incompreendido", se não oferecer nenhuma doutrina. Ele oferece assim doutrinas enfáticas, mas de um modo que permite entrever que não se trata de doutrinas no sentido ordinário. Ele faz concessão aos que procuram por doutrinas, proferidas nas "cátedras da virtude", para encontrar um "sentido da vida". Eles não podem proceder de outro modo; além disso, ele será mal compreendido por eles e, por isso, quer ser mal compreendido. Contudo, os "que não tem necessidade de nenhum artigo de fé extremo" (XII, 5(71) - Lenzer Heide - Fragment), talvez reconhecerão nas doutrinas de Zaratustra anti-doutrinas. As doutrinas de 
Zaratustra parecem ser pensadas de tal modo que elas distinguem os que precisam de doutrinas, dos que não têm mais necessidade delas. Nietzsche as denomina de "pensamentos", que atuam "seletivamente", e devem agir de modo "disciplinador" (2009, p. 27).

No contexto da grande saúde que extrapola o espaço institucional em que habitamos, a ideia do cultivo de si quer nos provocar a pensar sobre o pensamento do além-do-homem, que seria o pensamento de homens para além de todas as normatizações. Esses homens não precisariam mais de "artigos de fé", ou seja, de regulações estáveis e fixas. Esses homens não estão por aí, mas desejamos nos orientar pelo menos a cada instante nesta direção. Esse homem nasce com a possibilidade de criar e segundo Nietzsche "avaliar é criar: ouvi isso, oh criadores! O próprio avaliar é tesouro e jóia para todas as coisas avaliadas" (NIETZSCHE, 2011, "De mil e um alvos").

O Zaratustra é a obra de criação de Nietzsche que, ao poetar, avaliar e criar, expressa aquilo que cultivou em si mesmo para além de qualquer previsibilidade no campo filosófico. De fato, tornou-se filósofo ao produzir sua própria filosofia, sem orientar-se por aquilo que já estava à disposição.

Como seria a nossa obra pedagógica produzida por um desejo de avaliar e criar? Quais os nossos alvos? Saberemos rir de nós mesmos ao nos deparar com aquilo que antes nos orientava e parecia sagrado? Segundo Stegmaier: "O riso liberta da identificação a uma moral, sem dissolvê-la; ele permite distanciar-se dela, sem destruí-la; ele chama a atenção para ela, sem romper com ela" (2009, p. 43). O riso permite manter uma relação de liberdade com a moral para também avaliá-la como condutora de nossa ação. O cultivo de si, quando tomado como um compromisso consigo mesmo, faz aparecer o que antes era sério demais e agora implica saber rir de si, dançar, transvalorar, criar e desligar-se de uma velha moral e, em nossa análise, significa dizer uma determinada moral pedagógica a ser superada.

Promover a vida nas instituições deve ser um compromisso do Estado, mas nem toda vida possível poderá ser providenciada por qualquer sistema. Nesse labirinto que existe nos entremeios da instituição, podemos criar outra vida, outra pedagogia, outra relação mestre e discípulo que acontece como desejo de uma 
grande saúde pedagógica desdobrada em experiência que nunca se fixa, por vezes fracassa, mas sempre pode outra vez afetar nosso corpo.

Assim, a defesa desse artigo é pensar e criar espaços nas instituições para o cultivo de si na perspectiva do aluno e do mestre para que os sistemas não reduzam nossa capacidade de afirmar a vida a seus próprios propósitos. Por isso, o sujeito precisa ainda estar entre nós, de uma forma singular, como já explicado anteriormente. Os efeitos disso podem ser os mais singelos, não teremos certamente condições de produzir um Zaratustra pedagógico e tampouco imaginar-se um Nietzsche, mas por meio deles sentir os fios emaranhados que estão próximos de nós, para com eles criar e avaliar de onde são tecidos e porque desejam nos envolver em suas tramas e tecidos, além de como poderemos tomá-los a nosso favor para tecer outras tramas.

Nesse ponto, já podemos afirmar que Nietzsche, ao apresentar sua abordagem sobre o sujeito, não está interessado em destruir outras abordagens, mas decifrar os diferentes matizes de percepção do tema. Por isso, analisa o que Descartes e Kant anunciam. Não tem um lado para assumir e defender, Nietzsche nada tem a ver com a lógica bipolar visando a empurrar seus leitores para um dos lados, mas oferece argumentos para pensar.

A obra Zaratustra brinca com os opostos o tempo todo. O que para nós seria a grande razão, por exemplo, é apenas um brinquedo no jogo do corpo que seria essa grande razão. Esse corpo não é controlado totalmente pela razão e isso nos convida a pensar sobre quem é o sujeito em Nietzsche.

A perspectiva do cultivo de si caminha nessa direção, não está em questão dar ao eu autoridade, mas investigar quais cultivos nos perseguem, por meio dos quais somos seduzidos e como, enquanto artistas, podemos jogar com todos esses cultivos para inventar, representar e interpretar a si mesmo como um sujeito possível que joga com os processos de subjetivação já vividos nos termos expostos por Foucault.

\section{Considerações finais}

Portanto, em Nietzsche ainda existe um sujeito, em constante tensão por meio de uma multiplicidade de forças que seu próprio organismo provoca, mas 
existe a possibilidade de coordenação destas forças. Ao acessar esta condição, o indivíduo pode enfrentar valores onde o cultivo de certos tipos humanos designam sinais de decadência e aspirar valores afirmativos da vida que assegurem uma espécie de grande saúde. Ela virá de um enfrentamento, pois, como diz Nietzsche "a voz do rebanho ainda ressoará dentro de ti. E, quando disseres "Já não tenho a mesma consciência que vós", isso será um lamento e uma dor" (NIETZSCHE, 2011, p. 70). Contudo, será também a possibilidade de percorrer o caminho para ti mesmo.

Cuidar de si é um conceito que indica a possibilidade de outras práticas e outras formas de fazer educação que em alguma medida escapam da normatividade institucional, reconhecendo que ainda podemos e somos desafiados a tomar decisões, que preferencialmente podem ser éticas.

Nietzsche, por meio de sua genealogia, coloca em questão o sentido e o valor da verdade, entre elas o sentido da moral e nesta perspectiva, por meio de suas obras e de suas experiências, elabora perguntas, teses, suposições, problematizações. Foucault, inspirado por Nietzsche, procura analisar na história como esses dramas humanos se concretizam investigando ações, processos, práticas de todo tipo para em alguma medida, tanto um quanto outro, colocar em desordem o que parece absolutamente ordenado e regulado. Afinal, viver não implica obedecer às orientações que nos capturam, existem outras alternativas. E esse outro viver não cabe em nenhuma unidade e identidade prévia, de fato desliza para muitas direções em função de uma multiplicidade de forças e pulsões que rejeitam palavras como eu, alma e sujeito autônomo.

Deste modo, fica evidenciado pelos dois pensadores, Nietzsche e Foucault, que não há uma moral em si, mas interpretações moralizantes dos fenômenos, que não estabelecem conexões com eventuais causas específicas às prerrogativas da Vontade de Poder. Isso altera a concepção de verdade, pois ela é sempre um jogo, um arranjo de muitas possibilidades que dialogam com o poder. Foucault, por meio de sua ontologia do presente, consegue de alguma forma atualizar ainda mais os procedimentos genealógicos de Nietzsche ao indagar-se e fazer com que cada um possa pensar sobre isso: Como nos tornamos o que somos? $\mathrm{E}$ o que podemos recusar? O que ainda podemos criar? 
A indicação ética desta genealogia do presente em Foucault exige uma relação do sujeito consigo mesmo para decifrar coações, normatizações, disciplinamentos que direcionam sua vida. Cabe problematizar tais orientações e, num exame de si mesmo, cultivar outras práticas que ao constituírem-se fora das prescrições tradicionais acabam sendo de fato mais éticas, reconhecem o poder nas relações entre os humanos, contudo recusam e não permitem o poder converter-se em posse exclusiva de alguém ou de uma organização. Ou seja, a uma instituição não cabe arranjar contornos de formação, ela oferece possibilidades, e nesse jogo de forças e tensões podemos inventar outros arranjos estéticos desde que tenhamos cuidado do cultivo de nós mesmos, e nos ocupando de nós mesmos! Ainda que esse querer seja cheio de nuances e tensões, ele ainda é uma possibilidade e pode inaugurar outra pedagogia que implica uma autodeterminação, autoformação.

Assim, existe uma confluência de pensamento entre Foucault e Nietzsche, que lidos juntos em função de um tema - cultivo de si e/ou cuidado de si — afirmam e defendem uma "nova ética", a qual ainda tem referência num sujeito que necessita interpretar a si mesmo para oferecer a si mesmo, e também ao seu contexto social/político, a possibilidade de revelar um amor ao mundo onde a vida efetivamente encontra outras possibilidades de conduta e de valores. Essa afirmação é indigesta para educadores que imaginam fazer boa educação com efeitos globais e totalizantes, mas um desafio para educadores que defendem possibilidades singulares mesmo no interior das instituições. O cultivo de si favorece uma liberdade que se efetiva na ação de criar a si mesmo, que acontece por meio do domínio e coordenação de múltiplas forças e impulsos para efetivar um tipo de poder para diferenciar-se dos cultivos exigidos tradicionalmente.

O próprio Nietzsche tomou suas vivências como objeto de avaliação e um dos efeitos foi, por exemplo, o afastamento de Wagner. Assim "qualquer legítimo cultivo de si depende de um "longo exercício" do cuidado e do trabalho diário. Não se cultiva um caráter pleno de capacidades criativas aplicadas sobre o próprio modo de viver a partir da constante mudança de posturas" (TOMAZELLA BAPTISTA, 2015, p. 65). O cultivo de si e de outras vivências requer estabilizações de certos arranjos de forças para, de forma efetiva, possibilitar as criações significativas e a 
própria vida como um todo. Nesse ponto, podemos voltar ao personagem Zaratustra. Ele é a própria expressão de novas vivências, algumas fracassam, outras são apenas ensaiadas, mas por fim ele deseja enfrentar o niilismo e mostrar seu amor à humanidade e à terra. E parece que esta vivência e cultivo nos alcançam até hoje, pois em alguma medida arranjamos forças para estabilizar um novo valor. Mas, lembremos, Zaratustra é também uma antidoutrina, o personagem exige de nós que deixemos falar nosso si mesmo e nada aceitemos por mera autoridade. Então qual seria nossa proposta de vivência pedagógica? Atrelar-se apenas a políticas públicas e numa espécie de adesão cega fazer dela nossa vivência, ou deslocar-se entre os espaços da potência dessas políticas e também de suas fragilidades para tomar os fios emaranhados e tecer outras vivências possíveis?

Nossa tese nesse artigo foi defender a possibilidade de renovar a cultura a partir da afirmação de um estilo de vida capaz de escapar do barulho, cultivar o silêncio e a solidão como bem aponta Oliveira (2011), não para abandonar a sociedade, mas para contemplar a vida em todas as suas nuances para afirmar nosso amor ao mundo, à terra e a todos os sujeitos que conosco habitam as instituições educacionais. Nosso intento não foi em momento algum desqualificar as possibilidades de formação em espaços institucionais, contudo destacar a importância do cultivar a si mesmo, pois tais práticas instauram, permitem pensar de outras formas temas da Educação e, para além dela, a nós mesmos, sejamos alunos ou mestres.

\section{Referências}

ACAMPORA, C. D. As disputas de Nietzsche. Trad. Peterson R. Silva; Revisão técnica Jean G. Castro da Costa. Florianópolis: Editora da UFSC, 2018.

BOLSONI, B. V. O cuidado de si e o corpo em Michel Foucault: perspectivas para uma educação corporal não instrumentalizadora. In: IX ANPED SUL. Anais... Caxias do Sul, RS, 2012.

CONSTÂNCIO, J. A última vontade do homem, a sua vontade do nada: pessimismo e niilismo em Nietzsche. Revista Trágica: estudos sobre Nietzsche, v. 5, n. 2, p. 46-70, 2012.

CONSTÂNCIO, J. Palestra: Um mundo sem sujeito? Café Filosófico, 2017. Disponível em: <https://www.youtube.com/watch?v=EQQLsDNNh80>. Acesso em: 14 jun. 2019. 
COSTA DIAS, Luciana. Educar para quê? Observações acerca da Educação e Cultura a partir do pensamento de Friedrich Nietzsche . Natal RN, v. 1, n. 14, Out. 2016, 167-180.

FOUCAULT, M. Hermenêutica do sujeito. Trad. Márcio Alves da Fonseca. Salma Tannus Muchail. 2 ed. São Paulo: Martins Fontes, 2006.

ITAPARICA, A. L. M. Crítica à modernidade e conceito de subjetividade em Nietzsche. In: Estudos Nietzsche, Curitiba, v. 2, n. 1, p. 59-78, jan./jun. 2011.

MARCELLO, F. A.; FISCHER, R. M. B. Cuidar de si, dizer a verdade: arte, pensamento e ética do sujeito. Pro-Posições, v. 25, n. 2 (74) p. 157-175 maio/ago. 2014.

NIETZSCHE, F. Além do bem e do mal. Prelúdio a uma filosofia do futuro. Tradução, notas e posfácio de Paulo César de Souza. São Paulo: Companhia das Letras, 1992.

NIETZSCHE, F. Assim falava Zaratustra. Um livro para todos e para ninguém. Tradução, notas e posfácio de Paulo César de Souza. São Paulo Companhia das Letras. 2011.

NIETZSCHE, F. Ecce homo: como alguém se torna o que é. São Paulo: Companhia das Letras, 2008.

NIETZSCHE, F. Correspondência II - Abril 1869 a Diciembre de 1874. Tradução e notas de Andrés Rubio. Organização Luis Enrique de Santiago Guervós. Madrid: Editorial Trotta, 2012.

NIETZSCHE, F. Crepuisculo dos ídolos, ou, Como se filosofa com o martelo / tradução normas e posfácio Paulo Cesar de Souza. São Paulo: Companhia das Letras, 2006.

NIETZSCHE, Friedrich. A genealogia da moral. Trad. Mario Ferreira dos Santos. Petrópolis: Vozes, 2009.

NIETZSCHE, F. Escritos sobre educação. Trad. Noéli Correia de Melo Sobrinho, 2. ed. Rio de Janeiro: PUC-Rio; São Paulo: Loyola, 2003.

NIETZSCHE, F. Sobre o futuro dos nossos estabelecimentos de ensino. In. Escritos sobre educação: Friedrich Nietzsche. Tradução, apresentação e notas de Noéli Correia de Melo Sobrinho. $5^{\text {a }}$ ed. Rio de Janeiro: PUC-Rio; São Paulo: Ed. Loyola, 2003.

NIETZSCHE, F. III Consideração Intempestiva: Schopenhauer educador. In. Escritos sobre educação: Friedrich Nietzsche. Tradução, apresentação e notas de Noéli Correia de Melo Sobrinho. $5^{\text {a }}$ ed. Rio de Janeiro: PUC-Rio; São Paulo: Ed. Loyola, 2003.

OLIVEIRA, J. R. A profilaxia do silêncio.ethi@, Florianópolis v. 10, n. 1, p. 133-155, jun. 2011.

PASCHOAL, A. E. Da crítica de Nietzsche ao sujeito ao sujeito de sua crítica. Cadernos Nietzsche, Guarulhos/P. Seguro, v. 39, n. 1, p. 93-119, jan./abr. 2018. 
SOBRINHO, N. C. M (Org.). A Pedagogia de Nietzsche. In: NIETZSCHE, F. W. Escritos sobre educação. 2 ed. Rio de Janeiro: PUC-Rio; São Paulo: Ed. Loyola, 2003.

STEGMAIER, W. Antidoutrinas. Cena e doutrina em Assim falava Zaratustra, de Nietzsche. Cadernos Nietzsche, v. 25, 2009.

TOMAZELLA BAPTISTA, M. O que significa ser livre e responsável? O Indivíduo soberano como ideal moral de Nietzsche. Estudos Nietzssche, Espírito Santo, v. 6, n. 1, p. 4265, jan./jun. 2015.

RECEBIDO: 21/08/2019

APROVADO: $12 / 11 / 2019$

RECEIVED: 08/21/2019

APPROVED: $11 / 12 / 2019$

RECIBIDO: $21 / 08 / 2019$

APROBADO: $12 / 11 / 2019$ 